\title{
Open Thoracotomy and Decortication for Chronic Empyema Thoracis: Our Experience
}

\author{
Abubakar Umar ${ }^{1}$, Salisu Ismail ${ }^{1}$, Abdullahi Abdulkarim Aitek ${ }^{2}$, Aliyu Abdulrahman ${ }^{2}$, Ibrahim Galadima ${ }^{2}$, Aminu Abbas ${ }^{3}$, Sirajo Haliru \\ Tambuwal ${ }^{3}$, Solomon Ukwuani I ${ }^{1}$, Isah Abdullahi ${ }^{1}$ and Moyijo Maishanu ${ }^{1}$ \\ ${ }^{1}$ Cardiothoracic Surgery Unit, Department of Surgery, Usmanu Danfodiyo university/Usmanu Danfodiyo university Teaching Hospital, Sokoto, Nigeria. \\ ${ }^{2}$ Department of Anaesthesiology and Intensive Care, Usmanu Danfodiyo university/Usmanu Danfodiyo university Teaching Hospital, Sokoto, Nigeria. \\ ${ }^{3}$ Pulmonology Unit, Department of Medicine, Usmanu Danfodiyo University/Usmanu Danfodiyo university Teaching Hospital, Sokoto, Nigeria.
}

*Corresponding Author: Abubakar Umar; Cardiothoracic Surgery Unit, Department of Surgery, Usmanu Danfodiyo university/Usmanu Danfodiyo University Teaching Hospital, Sokoto, Nigeria.

Received date: May 7, 2021; Accepted date: July 16, 2021; Published date: July 31, 2021.

Citation: Abubakar Umar, Salisu Ismail, Abdullahi A. Aitek, Aliyu Abdulrahman, Ibrahim Galadima, et al. (2021). Open Thoracotomy and Decortication for Chronic Empyema Thoracis: Our Experience. J Thoracic Disease and Cardiothoracic Surgery, 2(2); DOI: 10.31579/2693-2156/022

Copyright: (C) 2021, Abubakar Umar. This is an open access article distributed under the Creative Commons Attribution License, which permits unrestricted use, distribution, and reproduction in any medium, provided the original work is properly cited.

\begin{abstract}
Background: Empyema thoracis is defined as the presence of pus in the pleural space or a purulent pleural effusion. Chronic empyema is characterized by thickened visceral and parietal peels which hamper the ability of the affected lung to re-expand and requires definitive surgical intervention. In a resource constraint environment like our, open thoracotomy and decortication is the treatment of choice. The aim of this article is to review our experience with cases of chronic empyema thoracis that had thoracotomy and decortication
\end{abstract}

Materials and Methods: This is a descriptive and observational study. Medical records of patients who had thoracotomy and decortication on account of chronic empyema thoracis in the cardiothoracic surgery unit of our hospital between 2012 and 2020 were retrieved and reviewed. The information obtained from the records included gender, age, premorbid conditions, aetiology of empyema, cultures of pleural fluids, histology results of the cortex removed, duration of chest tube drainage, duration of hospital stay, postoperative complications and outcome.

Results: One hundred and eighty-five patients diagnosed with empyema thoracis were seen in the study period. Sixtyfive patients had thoracotomy and decortication on account of chronic empyema thoracis while the remaining 120 $(64.9 \%)$ had closed tube thoracostomy drain insertion. Male: female was 5:1, mean age at presentation 24.24 years with age ranging from 2 years to 70 years. Fourteen $(23.33 \%)$ were in the paediatric age group while the remaining $(76.67 \%)$ were adults. The aetiology of empyema was pneumonia in $36(60 \%)$. Streptococcus pneumoniae was the commonest organism isolated from pleural fluids of these patients accounting for $23.33 \%$. All patients underwent thoracotomy and decortication. The mean duration before surgery was 17 days with a range of 2 days to 40 days. The average duration of surgery was 2 hours. Chest tube was removed after an average of 7 days (range 5 to 33 days. Twenty-one patients (35\%) had complications. Average duration of drainage was 18.87 days and that of hospital stay was 36.74 days. There were 3 mortalities (5\%). The mean duration of follow-up was 3 months.

Conclusion: Chronic empyema thoracis is still common in our environment and presentation is usually very late. In our series, open thoracotomy and decortication was found to be an excellent procedure with low morbidity and mortality. Majority of our patients had good functional outcome with few complications.

Key words: empyema thoracis; thoracotomy; lung decortication; chronic empyema; cortex; SPSS; pleurodesis; endobronchial valves; pyoneumothoraces

\section{Introduction}

Empyema thoracis is defined as the presence of pus in the pleural space or a purulent pleural effusion [1]. Empyema is divided into three stages.
Stage I (acute exudative phase), Stage II (subacute fibrinopurulent phase), and Stage III (chronic organizing phase) [2,3]. An empyema lasting 4 weeks and beyond is classified as stage III or chronic empyema [4,5]. Chronic empyema is characterized by thickened visceral and parietal 
peels which hamper the ability of the affected lung to re-expand and requires definitive surgical intervention, i.e., decortication with or without lung resection and/or pleural space obliteration procedures like thoracoplasty and use of various muscle flaps [6,7]. Currently open thoracotomy and lung decortication is the most favoured approach especially in resource poor environment like ours, although in the past decade some studies have been published in favour of the video assisted thoracoscopic surgery (VATS) approach but this is not readily available in our environment $[8,9]$. We reviewed our experience with cases of chronic empyema thoracis that had thoracotomy and decortication.

\section{Materials and Methods}

Usmanu Danfodiyo University Teaching Hospital Sokoto is tertiary health centre located in the north-western part of Nigeria. This hospital receives patients from neighbouring states and Niger republic.

This is a descriptive and observational study. Medical records of patients who had thoracotomy and decortication on account of chronic empyema thoracis in the Cardiothoracic surgery unit of our hospital between 2012 and 2020 were retrieved and reviewed. The information obtained from the records included gender, age, premorbid conditions, aetiology of empyema, cultures of pleural fluids, histology results of the cortex removed, duration of chest tube drainage, duration of hospital stay, postoperative complications and outcome.

Chronic empyema was defined in accordance with the American Thoracic Society staging system, where stage III empyema corresponds to chronic empyema or the organizing stage. Fibroblasts migrate into the pleural cavity and produce an inelastic membrane, entrapping the lung and rendering it essentially functionless. This diagnosis was corroborated by illness durations of more than 15 days before definitive treatment as well as supportive imaging findings, such as radiological features of a thick cortex and constriction of the chest cavity [10].

A database was created using Excel sheet which was later exported to SPSS version for analysis.

All patients had a full preoperative by the managing team assessment including a full blood count, coagulation screen, renal and occasionally liver function testing. In addition, all patients had a chest radiograph and occasionally chest CT scan. The decision to operate was based on either chest X-ray with or without CT scan evidence of a pleural cortex (fibrothorax) with a pleural collection and symptoms consistent with chronic empyema thoracis $[11,12]$.
Our protocol initially consisted of using single lumen tube but subsequently we began to use double lumen tube for endotracheal intubation. The surgical approach was via a posterolateral thoracotomy incision to gain access into the pleural space. Surgery included evacuation of all purulent material and decortication with the aim of obtaining the complete lung expansion. In most cases, decortication of parietal pleura was partial and performed in accordance with the need for complete decortication of the visceral pleura. We routinely separated the diaphragm from the lung and from adhesions to promote as much obliteration of the empyema cavity as possible. Single chest tube was inserted and directed towards the apex at the end of the operation. The pleural cavity was copiously irrigated with warm saline. Thoracotomy wounds were closed in layers. Patients were extubated routinely in the operating room but in rare circumstances, they are extubated in the intensive care unit. All patients are transferred from the theatre to our intensive care unit for postoperative management for at least 24 hours irrespective of whether they require mechanical ventilation or vasopressors support or not. They are discharged to our high dependency unit after 24 or 48 hours.

Chest physiotherapy was commenced on the $2^{\text {nd }}$ day post-op but occasionally on the $1^{\text {st }}$ day post-op. Chest tube was removed when there was no air leakage and when the drainage was less than $100 \mathrm{ml}$ per day and serous. Follow-up took place in our surgical outpatient clinic.

\section{Results}

One hundred and eighty-five patients diagnosed with empyema thoracis were seen in our unit during the study period. Sixty-five patients had thoracotomy and decortication on account of chronic empyema thoracis while the remaining $120(64.9 \%)$ had closed tube thoracostomy drain insertion. Only case notes of 60 patients $(32.4 \%)$ were available for review. Fifty patients were males while 10 were females giving a male: female ratio of $5: 1$. The mean age was 24.24 years with age ranging from 2 years to 70 years. Fourteen $(23.33 \%$ ) were in the paediatric age group while the remaining $(76.67 \%)$ were adults. The aetiology of empyema was pneumonia in $36(60 \%)$, tuberculosis in $21(35 \%)$, trauma in $3(3.3 \%)$ and histoplasmosis in $1(1.67 \%)$. Penetrating chest injury was the commonest cause of post-traumatic empyema. One patient $(1.67 \%)$ had chronic empyema thoracis from traumatic bilothorax. Strept pneumoniae was the commonest organism that was isolated from pleural fluids of these patients accounting for $23.33 \%$. There was no growth in 17 patients (28.33\%). See fig. 1.

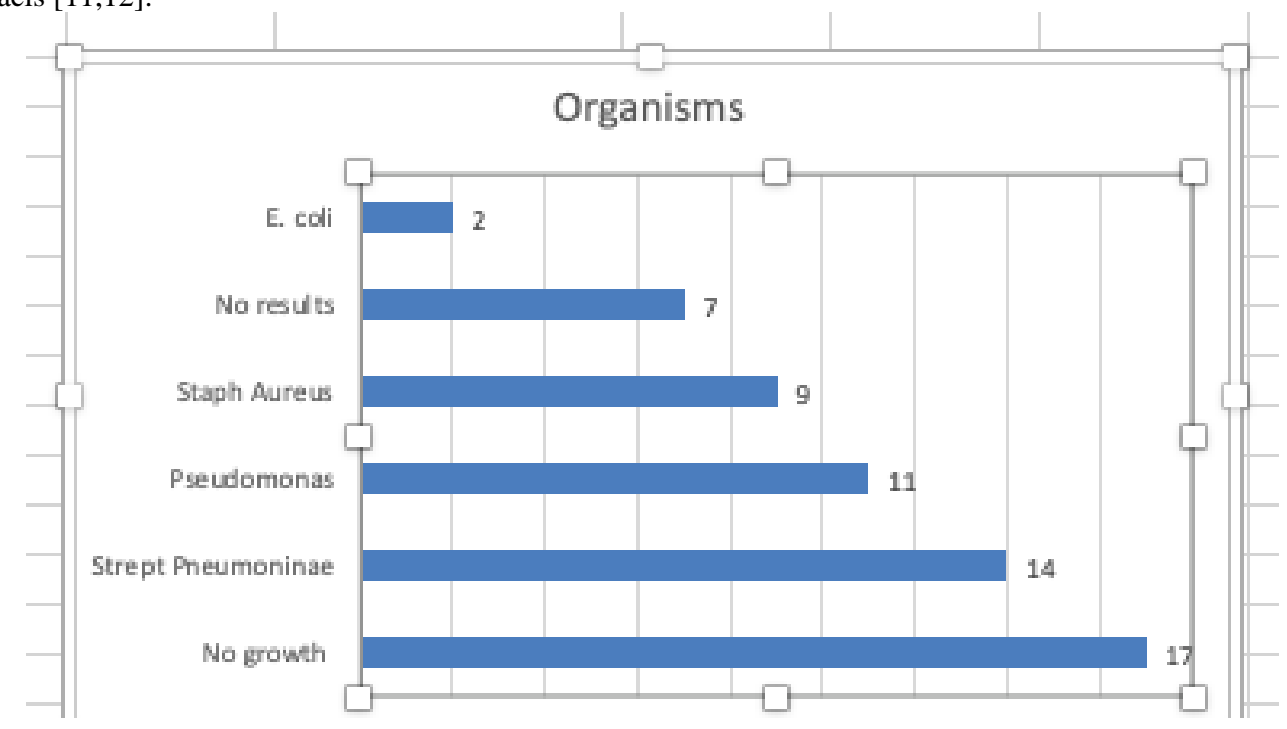

Figure 1. 
Associated comorbidities were hypertension in $6(10 \%)$, Diabetes mellitus in $4(6.67 \%)$ and human immunodeficiency virus infection in 2 $(3.33 \%)$. Forty-eight patients $(80 \%)$ had chest tube insertion before open thoracotomy and decortication. All patients underwent thoracotomy and decortication. Two patients $(3.33 \%)$ had bilateral thoracotomy and decortication done on same sitting. The mean duration before surgery was 17 days with a range of 2 days to 40 days. The average duration of surgery was 2 hours. Chest tube was removed after an average of 7 days (range 5 to 33 days. Twenty-one patients (35\%) had complications with persistent drainage accounting for $13.33 \%$, this was closely followed by persistent air leak (11.67\%). Average duration of drainage was 18.87 days and that of hospital stay was 36.74 days. There were 3 mortalities (5\%). One died intra-op while the remaining two died in the intensive care unit. The mean duration of follow-up was 3 months.

\section{Discussion}

Early treatment of empyema thoracis is advocated before it gets to the chronic organising stage. These forms of treatments include antibiotics, chest drain and the use of fibrinolytics [13].

However, there is a general consensus that chronic empyema thoracis be treated surgically either via open thoracotomy and decortication or video assisted thoracoscopic surgery $[14,15]$. This is to avoid the long-term complications of chronic empyema [16,17]. Unfortunately, in our environment, there is a delay in diagnosis, late presentation, failure to identify responsible organisms, inadequate antibiotic treatment, reluctance to drain, suboptimal drain placement at the referral centres and finally delay in referring to a thoracic surgeon. As such at these patients present in stage III, hence, the standard treatment is open thoracotomy and decortication. Video-assisted thoracoscopic surgery is not available in our centre and currently there is no expertise for that.

There is male preponderance in our series which is in keeping with most studies $[18,19]$. Majority of our patients were adults. Advancing age is known to be an acknowledged risk factor for both pneumonia and pleural empyema [20,21]. This is because some adults have pre-existing illnesses and other comorbidities as shown in our results. Diabetes mellitus and hypertension have been implicated in persistent drainage and recurrent empyema thoracis [22]. Pneumonia was the commonest cause of empyema in our series and Streptococcus Pneumoniae was the commonest organism isolated in pleural fluid samples. This is similar to other reports [18,23]. Others reported Staphylococcus aureus as the commonest causative organism isolated from pleural samples [24]. There was no growth in $17(28.33 \%)$ of our samples. This can be attributed to the use of several antibiotics before referral to our unit. Culture negative results have been reported in more than half of samples analysed in some studies $[18,25]$. This highlights the necessity in the use of other methods of bacterial detection like polymerase chain reaction. Pseudomonas aeruginosa was isolated in some of our patients. This is usually a hospital acquired infection [26]. In one of our patient histoplasma capsulatum was isolated in the pleural fluid. Histoplasma capsulatum has been shown to affect the lungs in various forms which can cause pleural effusion and subsequently empyema thoracis. It can cause acute pulmonary histoplasmosis, chronic cavitatory pulmonary histoplasmosis, granulomatous mediatinitis and mediastinal fibrosis [27-29]. Disseminated histoplasmosis has also reported especially in immunocompromised patient [30].

Eighty percent of our patients had chest tube insertion before thoracotomy and decortication. This is because presentation here is usually late and most at times in respiratory distress. As such, chest tube insertion is carried out to alleviate the respiratory symptoms. This also gives patient and caregiver time to source for funds to pay for surgery as payment for any form of surgery here for most patients is from "out-ofpocket" [31]. Only $20 \%$ whose presentation was not emergent that had thoracotomy and decortication without prior chest tube insertion. These are patients that presented to us in a stable clinical condition.

All our patients were treated with thoracotomy and decortication which is the standard treatment option for chronic empyema thoracis. There was a delay before definitive surgery in our series. This is mainly due to financial constraint as stated above because of lack of insurance cover [31]. Mean duration of drainage in our series was about 7 days which is in keeping with reports from other centres $[32,33]$. Others reported shorter duration $[18,34,35]$. Sixty five percent of our patient showed remarkable improvement and were discharged without complications. However, 35\% had various complications with persistent drainage been the commonest. Tantraworasin et al [36] reported a persistent drainage/recurrence in about $8.9 \%$ of their patients. They attributed this to residual space after decortication. They observed that most of these patients had thick cortex and, in some instances, calcified cortex as such, decortication was not successfully performed and full lung re-expansion was not achieved and this caused persistent space. Other identified factors were diabetes mellitus, hypertension and nonsepsis type of empyema. This is the case in some of our patient where in some cases the cortex was $2-3 \mathrm{~cm}$ thick. We managed some of these patients with empyema tube. They responded very well and tube subsequently removed after space has been obliterated with granulation tissues. Persistent air leak was another complication encountered in $11.6 \%$ of our patients which is defined as air leak longer than 5 days. This can be worrisome but studies have shown resolution of the leak as soon as complete lung re-expansion is achieved [37]. Majority of our patients were conservatively by watchful waiting and subsequently discharged between 2 and 3 weeks after resolution of the air leak. None of our patients required further intervention. Where there is complete lung re-expansion, pleurodesis has been advocated. Invasive methods of managing persistent air leaks have been report. Pneumoperitoneum instilled through a transabdominal catheter, unidirectional endobronchial valves, use of sealants and surgical re-exploration $[38,39]$.

Average duration of drainage was high in our series. This can be attributed to prolonged drainage after initial chest tube insertion prior to thoracotomy and decortication. When we matched duration of drainage and microscopy and culture, we discovered that those whose culture yielded pseudomonas had prolonged drainage compared to other organisms. Gram-negative bacillus such as Pseudomonas in the pleural space elicit an acute inflammation that affect polymorphonuclear cell response that precedes a monocyte-mediated fibroblast proliferation over the pleura which is necessary for cortex formation. The absence of which makes surgery difficult and marred with bleeding, air leak and bronchopleural fistula because there will be no clear plane between the cortex and pleura $[40,41]$. There were 3 mortalities in our series. The first mortality and second mortalities occurred very early in our unit. We were not using double lumen endotracheal tube then, these patients had pyoneumothoraces with bronchopleural fistula, we suspected that when they were positioned for surgery, they had soilage of the contralateral lungs which lead to persistent desaturation in the postop period in ICU. This was our turning point in our practice because from that time double lumen tube became the standard in our unit. The third mortality was a 68year-old known hypertensive who came in heart failure with chronic empyema thoracis. He was optimized and subsequently taken to the theatre. Intra-op he had cardiac arrest and all efforts to resuscitate him proved abortive.

\section{Conclusion}

Chronic empyema thoracis is still common in our environment and presentation is usually very late. In our series, open thoracotomy and decortication was found to be an excellent procedure with low morbidity and mortality. Majority of our patients had good functional outcome with few complications that were managed non-operatively. We therefore, 
advocate this form of treatment for patients which chronic empyema thoracis especially in resource constraint environments.

\section{References}

1. Light RW. (2006). Parapneumonic effusions and empyema. Proc Am Thorac Soc 2006; 3:75-80.

2. Mandal AK, Thadepalli H, Mandal AK, Chettipally U (1998). Outcome of primary empyema thoracis: therapeutic and microbiologic aspects. Ann Thorac Surg 1998; 66:1782-1786.

3. Edaigbini S, Anumenechi N, Odigie V, Khalid L, Ibrahim A (2013). Open drainage for chronic empyema thoracis; clarifying misconceptions by report of two cases and review of literature. Arch Int Surg 2013; 3:161.

4. Biswas A, Jantz MA, Penley AM, Mehta HJ (2016). Management of chronic empyema with unexpandable lung in poor surgical risk patients using an empyema tube. Lung India 2016; 33:267-271.

5. Jha VK, Singh RB (1972). Empyema of the thorax. Indian J Chest Dis 1972:14:243-248.

6. Jadczuk E (1998). Posptneumonectomy empyema. Eur J Cardiothorac Surg 1998; 14:123-126.

7. Kacprzak G, Marciniak M, Addae-Boateng E, Kolodziej J, Pawelczyk K (2004). Causes and management of postpneumonectomy empyemas: our experi-ence. Eur J Cardiothorac Surg 2004; 26:498-502.

8. Sahn S (1993). Management of complicated parapneumonic effusions. Am Rev Respir Dis 1993; 148:813 - 817.

9. Waller DA, Rengarajan A (2001). Thoracoscopic decortication: a role for video-assisted surgery in chronic postpneumonic pleural empyema. Ann Thorac Surg 2001; 71(6):1813-1816.

10. Melloni G, Carretta A, Ciriaco P, Negri G, Voci C, Augello G, et al (2004). Decortication for chronic parapneumonic empyema: results of a prospective study. World J Surg. 2004; 28:488-493.

11. Brixey AG, Luo Y, Skouras V, Awdankiewicz A, Light RW (2011). The efficacy of chest radiographs in detecting parapneumonic effusions. Respirology. 2011; 16:1000-1004.

12. Waite RJ, Carbonneau RJ, Balikian JP, Umali CB, Pezzella AT (1990), Nash G.Parietal pleural changes in empyema: appearances at CT.Radiology. 1990; 175:145-150.

13. Davies HE, Davies RJO, Davies (2010). CWH on behalf of the BTS pleural disease guideline group. Management of pleural infection in adults. British Thoracic Society Pleural Disease guideline 2010. Thorax2010; 65(2): ii41eii53.

14. Fraga JC, Kim P (2002). Surgical treatment of parapneumonic plearl effusion and its complications.J Pediatr. 2002; 78(2):161-173.

15. Balfour-Lynn IM, Abrahamson E, Cohen G, Hartley J, King S, Parikh D, Spencer , Thomson AH, Urquhart D (2005). On behalf of the Paediatric Pleural Diseases Subcommittee of the BTS Standards of Care Committee. BTS guidelines for the management of pleural infection in children. Thorax 2005;60(I): i1-i2.

16. Luh SP, Chou MC, Wang LS, Chen JY, Tsai TP (2005). Videoassisted thoracoscopic surgery in the treatment of complicated parapneumonic effusions or empyemas. Chest. 2005; 127:1427-1432.

17. Soriano T, Alegre J, Alemán $\mathrm{C}$, Ruiz E, Vásquez A, Carrasco $\mathrm{JL}$, et al (2005). Factors influencing length of hospital stay in patients with bacterial pleural effusion. Respiration. 2005; 72:587-593.

18. Okiror L, Coltart C, Bille A, Guil L, Pilling J, HarrisonPhipps K et al (2014). Thoracotomy and decortication: impact of culture-positive empyema on the outcome of surgery.
European Journal of Cardio-Thoracic Surgery 46 (2014) 901906.

19. Biswas A, Jantz MA, Penley AM, Mehta HJ (2016). Management of chronic empyema with unexpandable lung in poor surgical risk patients using an empyema tube. Lung India 2016; 33:267-271.

20. Arnold FW, LaJoie AS, Brock GN et al (2009). Improving outcomes in elderly patients with community-acquired pneumonia by adhering to national guidelines: CommunityAcquired Pneumonia Organization International cohort study results. Arch Intern Med 2009; 169: 1515-1524.

21. Schweigert M, Solymosi N, Dubecz A, Beron M, Thumfart L, Oefner-Velano D. et al (2012). Ann R Coll Surg Engl. 2012 Jul; 94(5): 331-335.

22. Tantraworasin A, Thepbunchonchai A, Siwachat S, Ruengorn C, Khunyotying D, Kaufman AJ, et al (2018). Factors associated with recurrent bacterial empyema thoracis. Asian Journal of Surgery (2018) 41, 313e320.

23. Marks DJ, Fisk MD, Koo CY, Pavlou M, Peck L, Lee SF et al (2012). Thoracic empyema: a 12-year study from a UK tertiary cardiothoracic referral centre. PLoS ONE 2012; 7: e30074.

24. Colice GL, Curtis A, Deslauriers J, et al (2000). Medical and surgical treatment of parapneumonic effusions: an evidencebased guideline. Chest 2000; 118: 1158-1171.

25. Hassan M, Cargill T, Harriss E, et al (2019). The microbiology of pleural infection in adults: a systematic review. Eur Respir J 2019; 54: 1900542.

26. Pal Ramprasad B, Rodrigues M, Datta S (2010). Role of Pseudomonas in nosocomial infection and biological characterization of local strain. J. Biosci Tech. 2010:1(4); 170179.

27. Gurney, J. W., and D. J. Conces, Jr (1996). Pulmonary histoplasmosis. Radiology 1996; 199:297-306.

28. Goodwin, R. A., Jr., F. T. Owens, J. D. Snell, W. W. Hubbard, R. D. Buchanan, R. T. Terry, and R. M. des Prez (1976). Chronic pulmonary histoplasmosis. Medicine (Baltimore) 1976; 55:413-452.

29. Davis, A., D. Pierson, and J. E. Loyd (2001). Mediastinal fibrosis. Semin. Respir. Infect. 2001; 16:119-130.

30. Kauffman, C. A., K. S. Israel, J. W. Smith, A. C. White, J. Schwarz, and G. F. Brooks (1978). Histoplasmosis in immunosuppressed patients. Am. J. Med. 1978; 64:923-932.

31. Aregbeshola BS, Khan SM (2018). Out-of-Pocket Payments, Catastrophic Health Expenditure and Poverty among Households in Nigeria 2010. Int J Health Policy Manag 2018, 7(9), 798-806.

32. Goyal V, Kumar A, Gupta M, Sandhu HP, and Dhir S (2014). Empyema thoracis in children: Still a challenge in developing countries. Afr J Paediatr Surg 2014; 11:206-210.

33. Andrade-Alegre R, Garisto JD, Zebede S (2008). Open thoracotomy and decortication for chronic empyema. clinics 2008;63(6):789-793.

34. Carey JA, Hamilton JRL, Spencer DA, Gould K, Hasan A (1998). Empyema thoracis: a role for open thoracotomy and decortication. Arch Dis Child 1998; 79:510-513.

35. Mohapatra, B., Sivakumar, P. \& Khan, M.S (2013). Role of decortication in management of parapneumonic empyema thoracis in children. Indian J Thorac Cardiovasc Surg. 2013: 29; 235-240.

36. Molnar TF (2007). Current surgical treatment of thoracic empyema in adults. Eur J Cardiothorac Surg 2007; 32:422-430.

37. Rocco G, (2010). Intraoperative measures for preventing residual air spaces. Thorac Surg Clin 2010; 20:371-375. 
38. Burt BM, Shrager JB (2014). Prevention and management of postoperative air leaks. Ann Cardiothorac Surg 2014; 3(2):216218.

39. Kovitz KL, French KD (2013). Endobronchial valve placement and balloon occlusion for persistent air leak: procedure overview and new current procedural terminology codes for 2013. Chest 2013; 144:661-665.
40. Anthony VB, Hadley KJ, Sahn SA (1989). Mechanism of pleural fibrosis in empyema. Chest 1989; 95(3):230S-231S.

41. Mandal AK, Thadepalli H, Mandal AK, (1998). Chettipally U.Outcome of primary empyema thoracis: therapeutic and microbiologic aspects. Ann Thorac Surg 1998; 66:1782-1786. (c) (?)

This work is licensed under Creative Commons Attribution 4.0 License

\section{To Submit Your Article Click Here: Submit Manuscript}

DOI: $10.31579 / 2693-2156 / 022$
Ready to submit your research? Choose Auctores and benefit from:

* fast, convenient online submission

* rigorous peer review by experienced research in your field

* rapid publication on acceptance

* authors retain copyrights

* unique DOI for all articles

* immediate, unrestricted online access

At Auctores, research is always in progress.

Learn more www.auctoresonline.org/journals/journal-of-thoracicdisease-and-cardiothoracic-surgery- 